\title{
Quality Assesment of Antibiotic Prescription for Sepsis Treatment in Intensive Care Unit at Top Referral Hospital in West Java, Indonesia
}

\author{
Shadrina Dinan Adani, ${ }^{1}$ Ardi Zulfariansyah, ${ }^{2}$ Putri Teesa $^{3}$ \\ ${ }^{1}$ Faculty of Medicine Universitas Padjadjaran, ${ }^{2}$ Department of Anesthesiology and Intensive \\ Care Faculty of Medicine Universitas Padjadjaran/Dr. Hasan Sadikin General Hospital Bandung, \\ ${ }^{3}$ Department of Anatomy, Biology Cell and Physiology Faculty of Medicine Universitas \\ Padjadjaran
}

\begin{abstract}
Background: Sepsis is a common disease in intensive care unit (ICU) with high mortality rate. Administration of antibiotic has an important role to determine the outcome of sepsis patient. This study aimed to evaluate the quality of antibiotic prescription for sepsis treatment in intensive care unit (ICU).

Methods: This descriptive study was conducted by retrieving data from 48 medical records of patients with sepsis, severe sepsis, and septic shock admitted to ICU Dr. Hasan Sadikin General Hospital (RSHS) in 2013. The study was conducted from August to October 2014. Empiric therapy in the ICUat RSHS and Surviving Sepsis Campaign (SSC) guidelines in 2012 were used as a standard for antibiotic prescription. The quality of antibiotic prescription was assessed then categorized based on Gyssens criteria. The collected data were analyzed in the form of frequency and percentage and presented in tables.

Results: This study discovered that most of the patients had severe sepsis and septic shock. Based on Gyssens criteria, 35\% antibiotic uses were included into category 0 (proper); $1.4 \%$ category I (improper timing); $10.5 \%$ category IIA (improper dosage); $9.1 \%$ category IIB (improper interval); $3.5 \%$ category IIC (improper route); $12.6 \%$ category IIIA (improper duration; too long); $1.4 \%$ category IIIB (improper duration; too short); $16.8 \%$ category IVA (improper; other antibiotics were more effective); $4.2 \%$ category IVD (improper; other antibiotics had narrower spectrum); and 5.6\% category V (improper; no indication). Conclusions: There are still improper uses of antibiotic for sepsis, severe sepsis, and septic shock patients in the ICU.
\end{abstract}

Keywords: Antibiotic, Glyssens criteria, sepsis, septic shock, severe sepsis

\section{Introduction}

Sepsis is a systemic response to infection that can result to severe sepsis (acute organ dysfunction caused by an infection that is already known in advance) and septic shock (severe sepsis plus hypotension that is not improved after fluid resuscitation). ${ }^{1}$ Sepsis is a common disease in Intensive Care Unit (ICU), in which 6-30\% patients treated have sepsis. ${ }^{2}$ A study in Spain reported the mortality of sepsis patients admitted to hospital; patients with sepsis are $12.8 \%$; patients with severe sepsis are $20.7 \%$; while patients with septic shock are $45.7 \%{ }^{3}$ In addition, another study in Spain reported that sepsis is the second largest cause of death in ICU with mortality in the first 48 hours of admission is $14.8 \%{ }^{4}$
Surviving Sepsis Campaign (SSC) guidelines in 2012 discussed about the management of severe sepsis and septic shock with the aim to improve the outcome of treatment, so that the incidence and mortality of sepsis will decrease. ${ }^{1}$ However, based on studies regarding treatment of patient with sepsis, it turns out that there are still treatments or actions that are not according to SSC guidelines, thus, morbidity and mortality increase. ${ }^{5}$ One of the treatments that is still not appropriate according to SSC guidelines is antibiotic treatment. Because there is no study data regarding antibiotic uses in the ICU at Dr. Hasan Sadikin General Hospital (RSHS) Bandung, especially in patients with sepsis, severe sepsis, and septic shock, this study was conducted to assess the quality of antibiotic

Correspondence: Shadrina Dinan Adani, Faculty of Medicine, Universitas Padjadjaran, Jalan Raya Bandung-Sumedang Km.21, Jatinangor, Sumedang, Indonesia, Phone: +62 8561101115 Email: dinanshadrina@yahoo.com 
prescription in patients with sepsis, severe sepsis, and septic shock in the ICU at RSHS Bandung in 2013.

\section{Methods}

The study was conducted from August to October 2014 using quantitative descriptive study method. The study was approved by the Health Research Ethics Committee
RSHS Bandung. The data were collected retrospectively using secondary data recorded in the Medical Record Installation RSHS. Samples were then determined by total sampling technique including patients with sepsis, severe sepsis, and septic shock admitted to ICU in 2013. The data collected from medical records were patient demographics (name, age, and gender), indication (diagnosis and results of culture examination with its resistance to antibiotic), name of administered

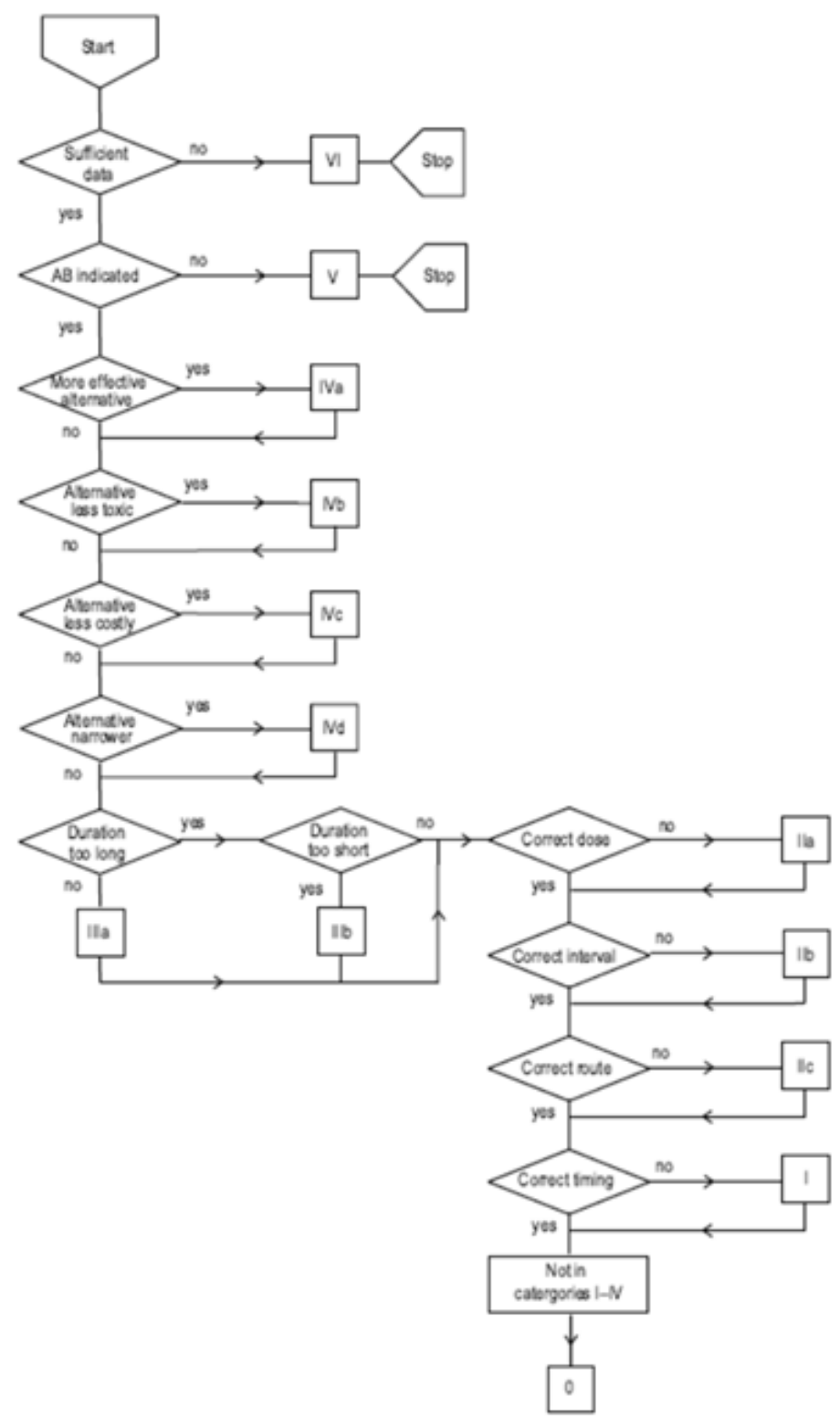

Figure 1 Flow Chart for Evaluation of Antibiotic Prescription

Source: Gyssens et al. ${ }^{6}$ 
Table 1 Distribution of the Number of Sepsis, Severe Sepsis, and Septic Shock Cases based on the Characteristics of the Patients

\begin{tabular}{lcccc}
\hline Variable & $\begin{array}{c}\text { Sepsis } \\
\mathbf{n ( \% )}\end{array}$ & $\begin{array}{c}\text { Severe Sepsis } \\
\mathbf{n ( \% )}\end{array}$ & $\begin{array}{c}\text { Septic Shock } \\
\mathbf{n ( \% )}\end{array}$ & $\begin{array}{c}\text { Total } \\
\mathbf{n}(\%)\end{array}$ \\
\hline Age & & & & \\
17-50 years old & $4(26.7)$ & $4(30.8)$ & $9(45)$ & $17(35.4)$ \\
$\begin{array}{l}\text { 51-87years old } \\
\text { Gender }\end{array}$ & $11(73.3)$ & $9(69.2)$ & $11(55)$ & $31(64.6)$ \\
Female & & & & \\
$\quad$ Male & $7(46.7)$ & $8(40)$ & $6(46.2)$ & $21(43.8)$ \\
Total & $8(53.3)$ & $12(60)$ & $7(53.8)$ & $27(56.3)$ \\
& 15 & 20 & 13 & 48 \\
\hline
\end{tabular}

antibiotic, dose, timing, route, frequency, and its duration of administration; also mortality.

The antibiotic prescriptions in the ICU at RSHS were adjusted to the standard of empiric therapy (guidelines of antibiotic use that have been agreed and should be applied in the ICU at RSHS) and also prescription uses were then assessed using flow chart of Gyssens criteria 2001 (Figure 1) that was divided into 0-VI category, namely proper use of antibiotic

Table 2 Distribution of Quality of Antibiotic Uses based on the Severity of Sepsis

\begin{tabular}{|c|c|c|c|c|}
\hline Variable & $\begin{array}{l}\text { Sepsis } \\
\text { n(\%) }\end{array}$ & $\begin{array}{c}\text { Severe Sepsis } \\
\text { n(\%) }\end{array}$ & $\begin{array}{c}\text { Septic Shock } \\
\text { n(\%) }\end{array}$ & $\begin{array}{l}\text { Total } \\
\text { n (\%) }\end{array}$ \\
\hline \multicolumn{5}{|l|}{ Indication } \\
\hline Proper indication & $33(97)$ & $43(87.8)$ & $34(97.1)$ & 110 (93.2) \\
\hline Improper indication & $1(3)$ & $6(12.2)$ & $1(2.9)$ & $8(6.8)$ \\
\hline \multicolumn{5}{|l|}{ Antibiotic } \\
\hline Proper antibiotic & 25 (75.8) & $29(67,4)$ & $26(76.5)$ & $80(72.7)$ \\
\hline Improper antibiotic & $8(24.2)$ & $14(32.6)$ & $8(23.5)$ & $30(27.3)$ \\
\hline \multicolumn{5}{|l|}{ Timing } \\
\hline Proper timing & $33(100)$ & $41(95.3)$ & $34(100)$ & $108(98.2)$ \\
\hline Improper timing & $0(0)$ & $2(4.7)$ & $0(0)$ & $2(1.8)$ \\
\hline \multicolumn{5}{|l|}{ Dose } \\
\hline Proper dose & 29 (87.9) & $40(93)$ & $26(76.5)$ & $95(86.4)$ \\
\hline Improper dose & $4(12.1)$ & $3(7)$ & $8(23.5)$ & $15(13.6)$ \\
\hline \multicolumn{5}{|l|}{ Route } \\
\hline Proper route & $30(90.9)$ & $41(95.3)$ & $34(100)$ & 105 (95.5) \\
\hline Improper route & $3(9.1)$ & $2(4.7)$ & $0(0)$ & $5(4.5)$ \\
\hline \multicolumn{5}{|l|}{ Interval } \\
\hline Proper interval & $28(84.8)$ & $39(90.7)$ & $30(88.2)$ & $97(88.2)$ \\
\hline Improper interval & $5(15.2)$ & $4(9.3)$ & $4(11.8)$ & 13 (11.8) \\
\hline \multicolumn{5}{|l|}{ Duration } \\
\hline Proper duration & $22(66.7)$ & $36(83.7)$ & $32(94.1)$ & $90(81.8)$ \\
\hline Too long & $10(30.3)$ & $6(14)$ & $2(5.9)$ & $18(16.4)$ \\
\hline Too short & $1(3)$ & $1(2.3)$ & $0(0)$ & $2(1.8)$ \\
\hline
\end{tabular}


Table 3 Distribution of Quality of Antibiotic Uses based on Gyssens Criteria

\begin{tabular}{lcc}
\hline \multicolumn{1}{c}{ Gyssens Criteria } & Amount (n) & Percentage (\%) \\
\hline Category 0 & $\mathbf{5 0}$ & $\mathbf{3 5 \%}$ \\
Category I & 2 & $1.4 \%$ \\
Category IIA & 15 & $10.5 \%$ \\
Category IIB & 13 & $9.1 \%$ \\
Category IIC & 5 & $3.5 \%$ \\
Category IIIA & 18 & $12.6 \%$ \\
Category IIIB & 2 & $1.4 \%$ \\
Category IVA & 24 & $16.8 \%$ \\
Category IVD & 6 & $4.2 \%$ \\
Category V & 8 & $5.6 \%$ \\
Total & 143 & $100 \%$ \\
\hline
\end{tabular}

(0); improper timing of administration (I); improper dose of administration (IIA); improper interval of administration (IIB); improper route of administration (IIC); improper duration of administration due to long administration (IIIA) and very short administration (IIIB); improper type of antibiotic due to other more effective antibiotics (IVA), other safer antibiotics with low toxicity (IVB), other cheaper antibiotics (IVC), other narrower spectrum antibiotics (IVD); improper indication (V); and the data in medical record were incomplete as well that could not be evaluated (VI). 6

The data were analyzed descriptively with quantitative approach in the form of frequencies and percentages presented in tables.

\section{Results}

There were 48 sepsis cases admitted to ICU in 2013, including $31.2 \%$ sepsis, $41.7 \%$ severe sepsis, and $27.1 \%$ septic shock. Most of the cases were found in males and in patients above 50 years old (Table 1 ).

There were 118 antibotic uses including 86 empiric therapies and 32 definitive therapies in 48 patients with sepsis, severe sepsis, and septic shock in the ICU. Improper uses of antibiotic were mostly due to incompatibility in the type of antibiotic and administration duration (Table 2).

The quality assessment of antibiotic prescription based on flow chart of Gyssens criteria were conducted in all administered antibiotics and obtained 143 units of analysis in 118 uses of antibiotics. The results of quality of antibiotic prescription in treatment of sepsis, severe sepsis, and septic shock in the ICU (category 0 Gyssens criteria) were found to be proper in 35\% of the antibiotic prescription (Table 3 ).

The incidence of mortality based on the severity of sepsis was found mostly prescription, mortality occurred more frequently in patients who received antibiotics improperly (56.3\%) (Table 4).

\section{Discussion}

Based on the study, incidence of sepsis, severe sepsis, and septic shock occurred more frequently in elderly patients ( $>50$ years old)

Table 4 Incidence of Mortality based on the Quality of Antibiotic Prescription and Severity of Sepsis

\begin{tabular}{lcccc}
\hline \multicolumn{1}{c}{ Mortality } & $\begin{array}{c}\text { Sepsis } \\
\mathbf{n ( \% )}\end{array}$ & $\begin{array}{c}\text { Severe Sepsis } \\
\mathbf{n ( \% )}\end{array}$ & $\begin{array}{c}\text { Septic Shock } \\
\mathbf{n ( \% )}\end{array}$ & $\begin{array}{c}\text { Total } \\
\mathbf{n}(\%)\end{array}$ \\
\hline Category 0 & $3(23)$ & $4(26.7)$ & $5(45.5)$ & $12(25)$ \\
Category I-V & $10(77)$ & $11(73.3)$ & $6(54.5)$ & $27(56.3)$ \\
Total & $13(33.3)$ & $15(38.5)$ & $11(28.2)$ & $39(81.3)$ \\
\hline
\end{tabular}


and male patients. This is in accordance with a study conducted by Martin et al. ${ }^{7}$ which found the incidence of sepsis increases by $20.4 \%$ in patients older than 60 years old and the possibility for male patients suffering from sepsis is higher than female patients. Old age is a risk factor for infection. The elderlies are vulnerable because their immune systems may not be able to fight infection. In general, elderly patients with chronic diseases may spend time in hospital much longer so that they become susceptible to the cause of infection. In addition, the use of medical devices such as catheters to the elderly patients also increases the risk of infection. ${ }^{8}$ Besides age, gender also affects the immune system. A study conducted by Aulock et al. ${ }^{9}$ in 2006 found differences in the immune defense capabilities between men and women. When there is an infection, blood in males produce more cytokines such as tumor necrosis factor-alpha (TNF- $\alpha$ ), interleukin-1 $\beta$ (IL-1ß), IL-6, and IL-8 in response to the high concentration of lipopolysaccharide (LPS) endotoxins from gram negative bacteria or lipoteichoic exotoxins from gram positive bacteria. If the inflammatory response is widespread and unregulated, it will cause men to be more susceptible to infection and sepsis. ${ }^{9}$

The quality of antibiotic prescription in patients with sepsis in the ICU was assessed using Gyssens criteria flow, including the indication of antibiotic, the type of administered antibiotic, the dose and route of administration, also the interval and duration of administration. ${ }^{6}$ This study discovered improper antibiotic prscription in all variables of those Gyssens criteria. A total of 110 administered antibiotics were given with a proper indication, while 8 other administered antibiotics not proper with the source of infection. Improper use of antibiotics most commonly found was choosing the type of antibiotics. Based on Gyssens criteria, selection of the type of antibiotic was considered proper if there is no other antibiotic which is more effective, with lower toxicity, or with narrower spectrum. ${ }^{6}$

Based on SSC guidelines, the choice of empirical antibiotic therapy should depend on sensitivity of pathogens that cause infections in hospital and patients clinical conditions such as drug intolerances, underlying disease, and clinical syndrome. Administered empirical antibiotic must be able to cover all possible pathogens that cause infections. After 3-5 days of empirical antibiotic administration, the management of sepsis patient continued with definitivetreatmentassoon as the susceptibility profile is known. ${ }^{1}$ This study discovered some selection of the type of empirical antibiotic combination that was less effective because it was not in accordance with the list of bacteria and its sensitivity to antibiotics at Dr. Hasan Sadikin General Hospital Bandung in 2013. Besides that, in some cases, even combination therapies were not given. This contrasts with the SSC guidelines which recommend the administration of combination therapy for patient with respiratory failure, septic shock, and infections due to multidrug-resistant (MDR) microbes. ${ }^{1}$ After the laboratory results of bacterial culture are obtained, if the sensitivity results are different with previous empiric therapy that was already given, empiric therapy is replaced with definitive therapy according to laboratory result. However, in some patients, there were still also found some resistant definitive antibiotic uses, which were not in accordance with culture result and its resistance from laboratory, such as ceftriaxone, ceftazidime, ciprofloxacin, and meropenem.

The second highest improper use of antibiotic was found in the duration of antibiotic treatment (Table 2). Based on SSC guidelines, empirical antibiotic combinations should not be used more than 3-5 days. Initiation of empiric antibiotic treatment should be evaluated periodically after $48-72$ hours based on the causal microbes and also the clinical condition of patient in order to give the narrower spectrum of antibiotic. If the test results of the sensitivity of bacteria have been known, definitive therapy should be given immediately. ${ }^{1}$ This study found a total of 18 empiric antibiotic treatments that are not in accordance with SSC guidelines because the treatment was given more than 5 days even more than 2 weeks. This is due to the culture results and resistances of bacteria that cause the infection was not obtained on time from laboratory, so the definitive therapy could not be administered. In this study, there were still many culture results and bacterial resistances obtained from laboratory for more than 5 days. In some cases, the culture and resistance examination were not even done. Excessive antibiotic treatment was not only detrimental to the patient in terms of cost, but also could cause bacteria to become resistant and increase in complication. Administered antibiotic for long time can cause side effects such as allergic reactions, antibiotic-associated colitis, and even death due to MDR.$^{10}$ Bacterial resistance to antibiotics occurs through the changes of bacterial genetic structure such as 
gene mutation. Genetic materials are capable of making the bacteria resistant through three main mechanisms, such as producing enzymes that inactivate or destroy antibiotics, changing the antibiotic target binding to the bacteria, and preventing access to the target itself. ${ }^{11}$

Improper use of antibiotic was also found in the dose of administration. In general, the maximum dose of antibiotic given to sepsis patients in this study was already proper; however, in some patients with kidney disorders such as acute kidney injury (AKI) in advanced stage, chronic kidney disease (CKD), and end stage renal disease (ESRD), there was still found antibiotic treatment with high dosage. Kidney failure can be triggered by nephrotoxic drugs such as antibiotics vancomycin, aminoglycosides, and betalactam group. Most of the classes of those antibiotics are excreted through the kidneys so that in patients with renal impairment, the dose given shoud be lower than the standard usually applied. ${ }^{12}$

Moreover, this study discovered that only $35 \%$ of antibiotic prescription for sepsis patients in the ICU at RSHS Bandung that was proper in accordance with the indication, type of antibiotic, timing, dose, route, interval, and duration (category 0 Gyssens criteria).

Mortality rate was still considerably high $(81.3 \%)$. The high incidence of mortality in sepsis patients can be caused by various factors, one of which is initiation of improper antibiotic treatment. Initial empiric antibiotic treatment that is adequate and continued with antibiotic treatment which is specific based on culture and its resistance result for sepsis patient treated in ICU is instrumental in determining outcome. ${ }^{13}$ Improper empiric and definitive antibiotic therapy effect on the outcome in this study, shown by incidence of mortality was more common in sepsis patient who received improper antibiotic treatment (56.3\%), while in sepsis patient who received proper antibiotic treatment, incidence of mortality were only $25 \%$ (Table 4 ). This result is suitable with previous study in the United States. The study reported the percentage of survival rates of septic shock patients who received proper antibiotic treatment are 52\%, while survival rates in patients who received improper antibiotic treatment are only $10.3 \%{ }^{14}$

Limitations of this study were incomplete data in medical records so that the quality of antibiotic prescription could not be evaluated maximally. Given the importance of proper antibiotic use in order to achieve better outcomes for sepsis patient in ICU, further study needs to be conducted qualitatively to determine the factors that can influence the quality of improper antibiotic use in patients with sepsis, severe sepsis, and septic shock in ICU.

Based on the result of this study, it can be concluded that there are still a lot of improper uses of antibiotics prescription in patients with sepsis, severe sepsis, and septic shock in the ICU at RSHS Bandung.

\section{References}

1. Dellinger RP, Levy MM, Rhodes A, Annane D, Gerlach H, Opal SM, et al. Surviving sepsis campaign: international guidelines for management of severe sepsis and septic shock: 2012. Crit Care Med. 2013;41(2):580-635.

2. Vincent JL, Sakr Y, Sprung CL, et al. Sepsis in European intensive care units: results of the SOAP study. Crit Care Med. 2006;34(2):344-353.

3. Esteban A, Frutos-Vivar F, Ferguson N, Penuelas O, Lorente JA, Gordo F, et al. Sepsis incidence and outcome: Contrasting the intensive care unit with the hospital ward*. Crit Care Med. 2007;35(5):1284-9.

4. Blanco J, Muriel-Bombin A, Sagredo V, Taboada F, Gandia F, Tamayo L, et al. Incidence, organ dysfunction and mortality in severe sepsis: a Spanish multicentre study. Crit Care. 2008;12(6):R158.

5. Herald Napitupulu. Sepsis. The Indonesian J Anesth Crit Care. 2011;28(3):207-15.

6. Van der Meer JWM, Gyssens IC. Quality of antimicrobial drug prescription in hospital. Clin Microbiol Infect. 2001;7(6):12-15.

7. Martin GS, Mannino DM, Moss M. The effect of age on the development and outcome of adult sepsis. Crit Care Med. 2006;34(1):15-21.

8. NHMRC.Prevention and control of infection in residential and community aged care.Canberra: Department of Health and Ageing; 2013.

9. Aulock SV, Deininger S, Draing C, Gueinzius $\mathrm{K}$, Dehus O, Hermann C. Gender difference in cytokine secretion on immune stimulation with LPS and LTA. J InterferonCytokine Res. 2006;26(12):887-92.

10. Hochreiter M, Köhler T, Schweiger AM, Keck FS, Bein B, Von Spiegel, et al. Procalcitonin to guide duration of antibiotic therapy in intensive care patients: a randomized prospective controlled trial. Crit Care. 2009;13(3):R83. 
11. Iwan Dwiprahasto. Kebijakan untuk meminimalkan risiko terjadinya resistensi bakteri di unit perawatan intensif rumah sakit. Jurnal Manajemen Pelayanan Kesehatan. 2005;8(4):177-81.

12. Pea F, Viale P. Bench-to-bedside review: appropriate antibiotic therapy in severe sepsis and septic shock - does the dose matter. Crit Care. 2009;13(3):R214.

13. Garnacho-Montero J, Garcia-Garmendia JL, Barrero-Almodovar A, Jimenez-Jimenez FJ,
Perez-Paredes C, Ortiz-Leyba C. Impact of adequate empirical antibiotic therapy on the outcome of patients admitted to the intensive care unit with sepsis. Crit Care Med. 2003;31(12):2742-51

14. Kumar A, Ellis P, Arabi Y, Roberts D, Light B, Parrillo JE, et al. Initiation of inappropriate antimicrobial therapy results in a fivefold reduction of survival in human septic shock. CHEST J. 2009;136(5):1237-48. 